\title{
Avaliação dos Efeitos da Adição de Emulsificante na Textura de Snacks Para Cães
}

\author{
M. M. BORTOLO ${ }^{1}$, D. R. MARQUES ${ }^{1}$, L. A. C. TONON ${ }^{1}$, G.S. MADRONA ${ }^{1}$, M.R.S. SCAPIM*1 \\ ${ }^{1}$ Universidade Estadual de Maringá, Departamento de Engenharia de Alimentos \\ *E-mail para contato: jprsgrss@yahoo.com.br
}

\begin{abstract}
RESUMO - Neste trabalho, estudou-se a aplicação de um emulsificante, em snacks para cães com o intuito de retardar o efeito da retrogradação do amido. Realizou-se testes de textura no texturômetro TAx $2 \mathrm{i}$, avaliando a textura do produto em embalagem aberta, durante 24 horas, simulando o uso pelo consumidor e em embalagem fechada durante 45 dias, simulando parte da vida de prateleira do produto. As isotermas de sorção foram traçadas pelo método gravimétrico, para os dois tratamentos. A dureza das amostras com emulsificante foi significativamente menor $(6,0047 \mathrm{Kgf})$ que das amostras sem emulsificante $(6,8470 \mathrm{Kgf})$, com embalagem aberta. A adição do emulsificante teve efeito positivo na manutenção da maciez do produto, mesmo após a abertura da embalagem.
\end{abstract}

\section{INTRODUÇÃO}

O mercado de produtos para pequenos animais, intitulado como mercado pet, se destaca a cada ano, tornando-se cada vez mais lucrativo. Em 2011, este setor apresentou lucros de $13 \%$ a mais que no ano de 2010. Isso significa um lucro de R\$ 12.439 bilhões. Deste faturamento, o segmento pet food representa aproximadamente $66 \%$, o que corresponde cerca de R $\$ 8.209$ bilhões (Revista Negócios Pet 2011).

Dentro deste mercado tem-se o seguimento dos "snacks" que são petiscos para os cães que podem ser fornecidos durante atividades recreativas, aprendizado e treinamento. Normalmente, são fornecidos ao animal com o intuito de promover a atenção, aprendizado e obediência com entreterimento. Eles podem ter funções nutricionais ou não, não devem ser utilizados para substituir a alimentação normal, já que a quantidade recomenda é aproximadamente 10\% de energia diária requerida pelos animais (ANFALPET, 2011).

Este produto é obtido por extrusão, podendo ser secos ou semi úmidos, a base de carne, torneados ou de diferentes formatos. Normalmente estes alimentos são ricos em amido, e após a abertura das embalagens o produto apresenta mudanças na textura, ocasionada principalmente pela retrogradação do amido . 
Assim a extrusão, determina o grau de gelatinização do amido, a desnaturação das proteínas, perdas de aminoácidos e vitaminas, além de provocar a expansão do produto (MURAKAMI, 2010).

O ganho ou a perda de umidade altera a atividade de água do produto, favorecendo as reações bioquímicas enzimáticas e não-enzimáticas, alterações na estrutura de macromoléculas como carboidratos e proteínas, e o crescimento de microrganismos. Assim, durante o armazenamento os alimentos ficam sujeitos as alterações na aparência, cor, odor, sabor e textura, perda no valor nutricional e aparecimento de compostos tóxicos microbianos (AZEREDO, 2004).

Segundo Murray et al. (2001), a quantidade de água influencia tanto nas propriedades físicas quanto na qualidade nutricional do produto, além de favorecer a menor viscosidade da massa. $\mathrm{O}$ excesso de água no decorrer do processamento refletirá principalmente na atividade de água do produto, consequentemente nas boas condições de estocagem. A falta de controle na quantidade de água pode causar também a incompleta gelatinização do amido, podendo afetar a digestibilidade e palatabilidade do produto.

As isotermas de sorção permitem avaliar a relação de equilíbrio entre a umidade do alimento e o teor de umidade presente no ambiente, ou a relação entre pressão de vapor de água no alimento e a pressão de vapor de água presente no ambiente a temperaturas e pressões constantes (SUN e WOOD, 1993).

A textura, na verdade, é um conjunto de propriedades, um conceito puramente sensorial, o qual a percepção pode se distinguir entre características: mecânicas, geométricas, de composição química, acústicas, visuais e térmicas (FISZMAN,1998). Desta maneira, esse conjunto de parâmetros sensoriais multidimensionais estão intimamente ligados à seleção e aceitação de um alimento. Portanto, a textura determina a escolha de matérias primas e ingredientes, equipamentos e condições operacionais, manipulação e conservação de produtos.

Os emulsificantes, apesar da diversidade, apresentam a mesma estrutura molecular. $\mathrm{Na}$ molécula coexistem uma porção hidrofílica, ou seja, que tem afinidade por água, e uma porção lipofílica, que tem afinidade por óleo ou outras substâncias apolares. Essa estrutura é responsável pelas propriedades dos emulsificantes, e faz com que eles tenham a capacidade de formar emulsões, tornando miscíveis substâncias normalmente imiscíveis (NUNES, 2004).

As cadeias de amilose presentes no amido formam complexos com os emulsificantes, onde a cadeia linear da amilose enrola-se na cadeia do emulsificante formando uma hélice. Os grupamentos $\mathrm{C}-\mathrm{H}$ e o átomo de oxigênio glicosídico se orientam para o interior, formando um núcleo lipofílico, com todos os grupamentos $\mathrm{OH}$, hidrofílicos, dirigidos para o exterior. $\mathrm{O}$ complexo formado entre o emulsificante e a amilose é insolúvel em água. Com isso, torna-se mais difícil a saída deste do interior do grânulo de amido, evitando a retrogradação do amido (PALMA, CICHELLO e PAVANELLI, 2004). 
O presente trabalho teve como objetivo estudar a atuação de ingredientes, como o emulsificante sobre a retrogradação do amido em "snacks" para cães. Serão estudados parâmetros de textura e atividade de água estabelecidos durante a vida de prateleira do produto após a abertura da embalagem e com a embalagem fechada.

\section{MATERIAIS E MÉTODOS}

Os snacks em pacotes de $80 \mathrm{~g}$ foram fornecidos pela empresa Brasilian Pet Foods, localizada em Arapongas-PR. O emulsificante utilizado foi MYVATEX 740® onde o componente principal é a goma Karaya, fornecido pela empresa Kerry. A quantidade deste aditivo não foi revelada pela empresa, e foi adicionado juntamente com os demais ingredientes.

As isotermas de sorção das amostras foram determinadas em triplicata. As amostras foram colocadas em recipientes contendo diferentes soluções saturadas dos seguintes sais: Cloreto de sódio, Cloreto de Lítio, Carbonato de Potássio, Nitrato de Magnésio, Nitrato de Sódio, Cloreto de Potássio, Nitrato de Magnésio, com faixa de atividade de água de 0,11 a 0,90, sob temperatura de $25 \mathrm{oC}$ até atingirem a umidade de equilíbrio. A umidade final das amostras foi determinada pelo método gravimétrico de secagem em estufa a $105 \mathrm{oC}$ por 24 horas. Com os dados obtidos traçouse um gráfico de gramas de água/ gramas de amostra seca versus umidade relativa (ARNOSTI, 1997).

Com relação a textura os snacks foram avaliados durante 24 horas, em um intervalo de 2 em 2 horas, com embalagem aberta e durante 45 dias com intervalo de 15 em 15 dias, com a embalagem fechada, utilizando um texturômetro TaX2i. As amostras foram dispostas horizontalmente sobre a plataforma e utilizou-se o probe Warner Bratzler (HDP/BS) para romper a amostra como uma guilhotina, a carga máxima utilizada foi de $5 \mathrm{~kg}$. Os resultados (média aritmética de 10 determinações) foram expressos em Kgf e representavam a de força de ruptura. Os parâmetros utilizados nos testes foram: velocidade pré-teste $=1,5 \mathrm{~m} / \mathrm{s}$; velocidade de teste $=$ $2,0 \mathrm{~m} / \mathrm{s} ;$ velocidade pós-teste $=10,0 \mathrm{~m} / \mathrm{s} ;$ força $=0,20 \mathrm{~N}$.

Avaliando o parâmetro de dureza do produto, tanto em embalagem aberta, quanto em embalagem fechada as amostras foram submetidas ao cisalhamento. Os dados foram submetidos a uma análise estatística de variância (ANOVA) e aqueles que apresentaram diferença significativas submetidos ao teste de Tukey.

As análises feitas nas amostras com a embalagem aberta simularam a utilização do produto, uma vez que este possui diversas partículas, não sendo consumido inteiro em apenas um dia. Quanto às análises feitas no produto com a embalagem fechada, simula a estadia do produto na prateleira do estabelecimento em que vai ser comercializado. 


\section{RESULTADOS E DISCUSSÃO}

Na Tabela 1 estão dispostos os resultados da análise de variância (ANOVA), dos testes de textura para embalagem aberta, no decorrer de 24 horas.

Ao analisarmos os dados das amostras com emulsificante (Tabela 1), comparando entre os tempos, houve diferença significativa do tempo $0,2,6$ e 12 para o tempo de 24 horas e do tempo 8 para o tempo de 12 horas. Nas amostras sem emulsificantes todos os tempos tiveram diferença significativa em relação ao tempo de 24 horas. Ou seja, nota-se que a força de cisalhamento exercida pelo texturômetro aumentou conforme o decorrer do tempo, mostrando assim que ocorrem alterações na textura do produto, a medida que as horas se passam.

Tabela 1: Valores médios para análise de dureza (Kgf) para Embalagem Aberta.

\begin{tabular}{|c|c|c|}
\hline Tempo (horas) & Com emulsificante & Sem emulsificante \\
\hline 0 & $5,843 \pm 0,19^{\mathrm{b}, \mathrm{A}}$ & $6,580 \pm 0,332^{\mathrm{A}}$ \\
\hline 2 & $5,693 \pm 0,341^{\mathrm{b}, \mathrm{A}}$ & $6,025 \pm 0,308^{\mathrm{A}}$ \\
\hline 4 & $6,144 \pm 0,542^{\mathrm{a}, \mathrm{b}, \mathrm{A}}$ & $6,455 \pm 0,518^{\mathrm{A}}$ \\
\hline 6 & $5,673 \pm 0,227^{\mathrm{b}, \mathrm{A}}$ & $5,9610,142^{\mathrm{B}}$ \\
\hline 8 & $6,370 \pm 0,273^{\mathrm{a}, \mathrm{A}}$ & $6,227 \pm 0,249^{\mathrm{A}}$ \\
\hline 12 & $5,387 \pm 0,289^{\mathrm{b}, \mathrm{A}}$ & $6,336 \pm 0,420^{\mathrm{B}}$ \\
\hline 24 & $6,913 \pm 0,659^{\mathrm{a}, \mathrm{b}, \mathrm{A}}$ & $10,343 \pm 1,221^{\mathrm{c}, \mathrm{B}}$ \\
\hline
\end{tabular}

* Letras minúsculas na mesma coluna não diferem entre si a 5\% de probabilidade pelo Teste de Tukey.

* Letras maiúsculas na mesma linha não diferem entre si a 5\% de probabilidade pelo Teste de Tukey.

Estabelecendo uma comparação dos resultados das amostras com e sem emulsificantes, mostrados na Tabela 1, houve diferença significativa na força de cisalhamento do texturômetro entre as amostras no tempo 0, 6, 12 e 24, essa diferença se da pelo efeito do emulsificante aplicado. Através da Figura 1, pode-se perceber tal efeito.

Observando-se a Figura 1, nota-se que as amostras com emulsificantes apresentaram menor dureza que as amostras sem emulsificante. Isso acontece pois o emulsificante atua retardando a retrogradação do amido. Segundo Krog, 1997, em uma revisão sobre a estrutura química e físico- química dos emulsificantes alimentícios, os emulsificantes interferem diretamente na retrogradação do amido e modificam a cristalização das gorduras melhorando a 
textura em alimentos, melhorando a qualidade sensorial e prolongando a vida útil do produto. Esta diferença foi sutil até o tempo de 12 horas e ficou mais evidente após 24 horas de avaliação.

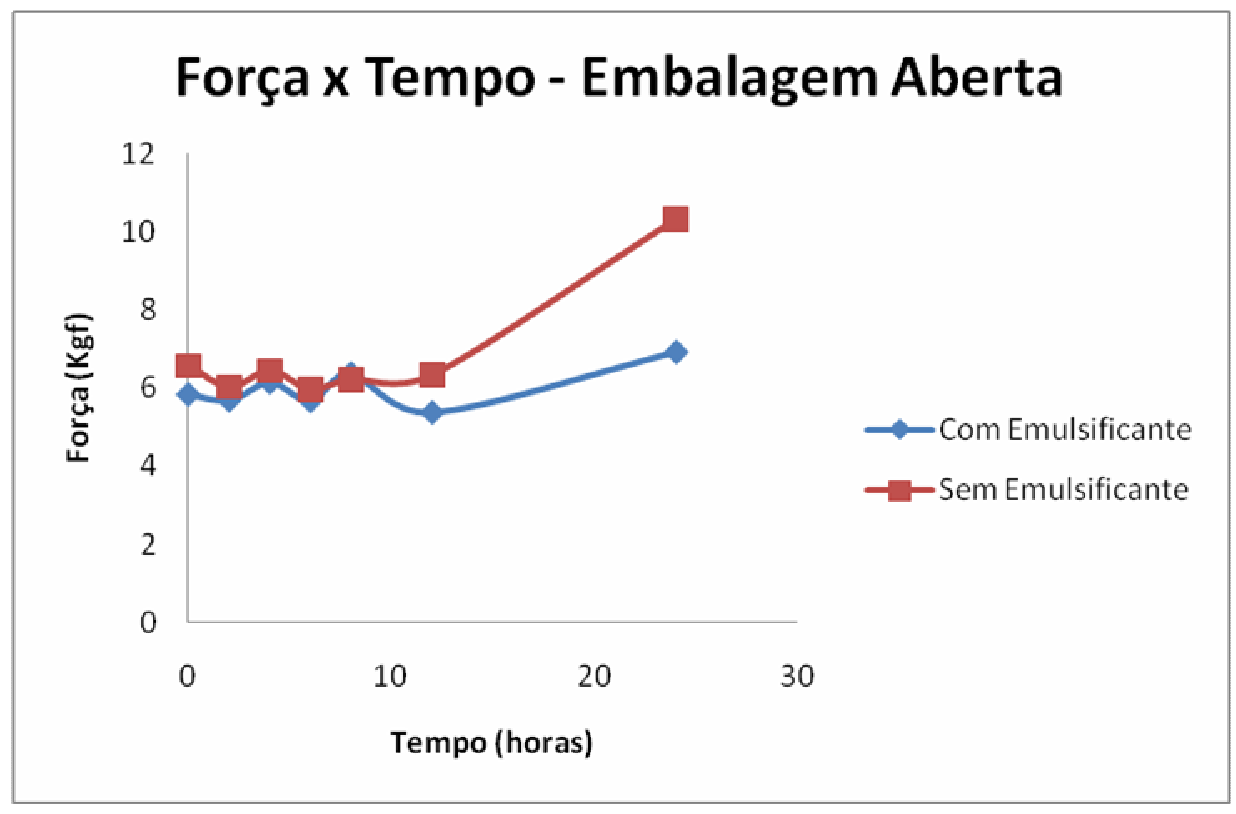

Figura 1: Força (Kgf) x Tempo (horas), para embalagem aberta.

Na Tabela 2, estão dispostos os resultados da análise de estatística de variância (ANOVA), para as amostras com e sem emulsificantes com embalagem fechada.

Relacionando os dados obtidos para a amostra com emulsificante entre os diferentes tempos, observou-se diferença significativa do tempo 0 e 15 em relação ao tempo 30 , do tempo 15 em relação ao tempo 45. Nos dados sem emulsificante, também comparados entre si, houve diferença significativa no tempo 0 e 15 em relação ao tempo 30 e do tempo 15 para o tempo 45. Mesmo com a embalagem fechada também ocorrem alterações na textura do alimento, durante a sua vida de prateleira.

Ao compararmos os dados da Tabela 2, estabelecendo uma relação entre a amostra com emulsificante e sem emulsificante, observa-se diferença significativa entre as amostras no tempo 0 e no tempo 30. Ou seja, com a embalagem fechada também temos alterações na textura do produto, mas aos 45 dias esta diferença não foi observada.

Considerando que o produto demora aproximadamente 30 dias para chegar ao consumidor e que o tempo de vida útil total do produto é de oito meses, os resultados observados (Figura 2), não são muito animadores. Pois após 45 dias de fabricado o produto com emulsificante apresenta a mesma dureza da amostra sem emulsificante. 
O ideal seria que as análises continuassem durante todo esse período, para que pudéssemos estudar o efeito do emulsificante durante toda a shelf-life do produto para a embalagem fechada, pois segundo Krog, 1989, para pães os emulsificantes a base de monoglicerídeos tem grande eficácia no retardo da retrogradação do amido em longos períodos de armazenamento.

Tabela 2: Valores médios para análise de dureza (Kgf) para embalagem fechada.

\begin{tabular}{|c|c|c|}
\hline Tempo (dias) & Com emulsificante & Sem emulsificante \\
\hline 0 & $5,843 \pm 0,199^{\mathrm{c}, \mathrm{A}}$ & $6,580 \pm 0,332^{\mathrm{e}, \mathrm{f}, \mathrm{B}}$ \\
\hline 15 & $5,861 \pm 0,297^{\mathrm{c}, \mathrm{A}}$ & $6,176 \pm 0,303^{\mathrm{f}, \mathrm{A}}$ \\
\hline 30 & $6,693 \pm 0,206^{\mathrm{a}, \mathrm{b}, \mathrm{A}}$ & $7,638 \pm 0,420^{\mathrm{d}, \mathrm{e}, \mathrm{C}}$ \\
\hline 45 & $7,278 \pm 0,471^{\mathrm{a}, \mathrm{b}, \mathrm{A}}$ & $7,010 \pm 0,318^{\mathrm{e}, \mathrm{d}, \mathrm{A}}$ \\
\hline
\end{tabular}

* Letras minúsculas na mesma coluna não diferem entre si a 5\% de probabilidade pelo Teste de Tukey.

* Letras maiúsculas na mesma linha não diferem entre si a 5\% de probabilidade pelo Teste de Tukey.

Na Figura 3 tem-se a isoterma de sorção do produto com e sem emulsificante, a qual estabelece a relação de equilíbrio entre a umidade do alimento e o teor de umidade presente no ambiente (SUN e WOOD, 1993).

Pode-se observar (Figura 3) que nas amostras com emulsificantes, quanto maior a atividade de água do sal, maior a quantidade de água retida, enquanto que para as amostras sem emulsificante, a quantidade de água é constante. Segundo, GANDRA, 2008, para pães, a utilização de um alto teor de monoglicerídeos, gera uma maior retenção de umidade. Para PALMA, CICHELLO e PAVANELLI (2004), os emulsificantes formam complexos com a amilose, onde a cadeia linear da amilose enrolase na cadeia do emulsificante formando uma hélice.

Os grupamentos $\mathrm{C}-\mathrm{H}$ e o átomo de oxigênio glicosídico se orientam para o interior, formando um núcleo lipofílico, com todos os grupamentos $\mathrm{OH}$, hidrofílicos, dirigidos para o exterior. $\mathrm{O}$ complexo formado entre o emulsificante e a amilose é insolúvel em água. Com isso, torna-se mais difícil a saída deste do interior do grânulo de amido, evitando a retrogradação do amido. Dessa forma o emulsificante impede que o produto perca água para o ambiente, fazendo com que o produto apresente maior estabilidade. 


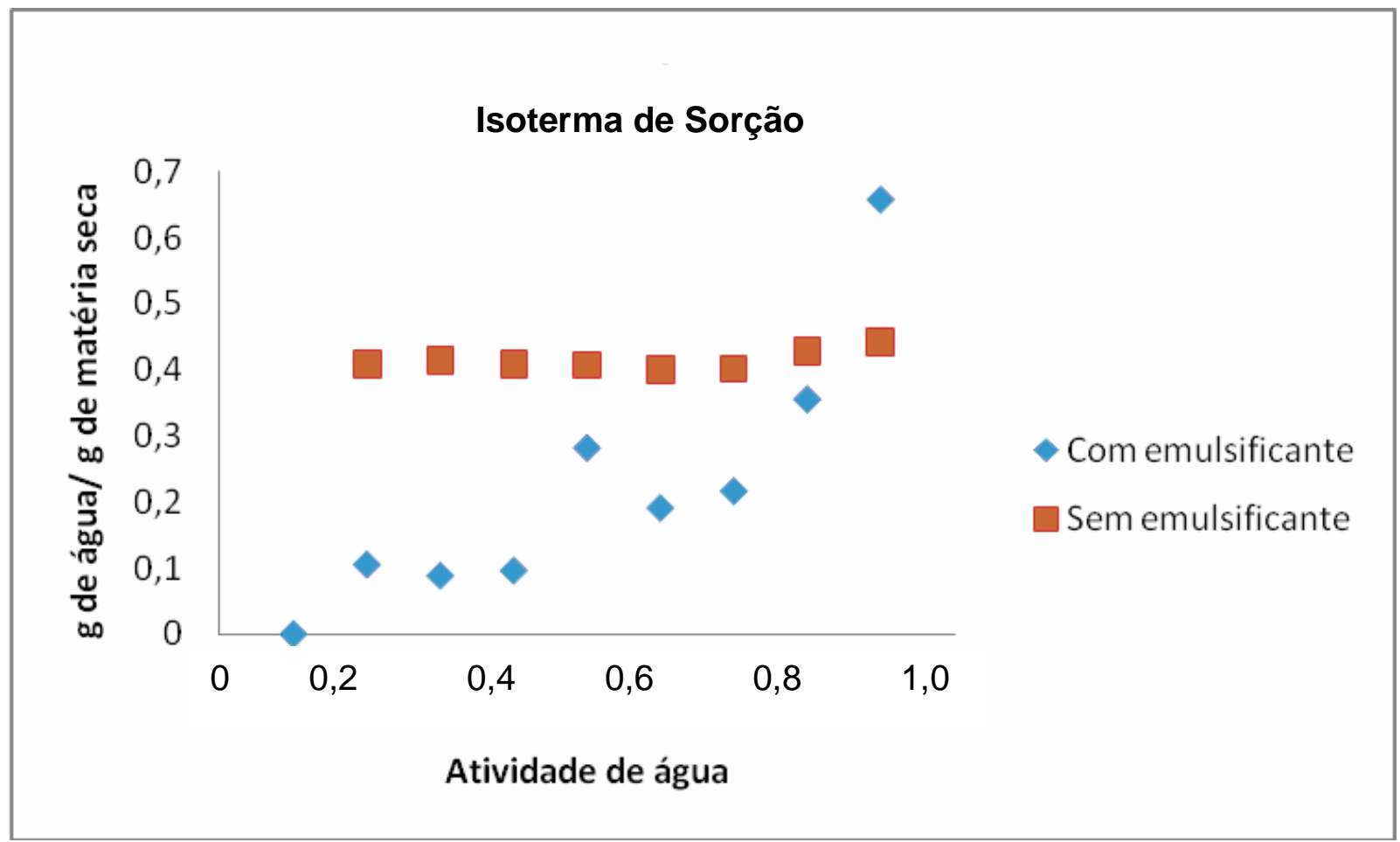

Figura 3: Isoterma de sorção

\section{CONCLUSÕES}

Com o decorrer do tempo a força de cisalhamento exercida pelo texturômetro sobre as amostras com emulsificantes foi significativamente menor em relação à exercida sobre as amostras sem emulsificante, para as análises do produto com embalagem aberta. As amostras com emulsificantes obtiveram maior teor de água, conforme o aumento da atividade de água dos sais. Esses resultados são fruto do efeito retardador do emulsificante sobre a retrogradação do amido e a expulsão da água. Mostrando assim que o objetivo do trabalho foi atingido.

Para as análises com embalagem fechada, sugere-se que os testes de textura perdurem durante toda a vida útil do produto, ou seja, 8 meses, para que se possa ver com precisão o efeito do emulsificante sobre a retrogradação do amido e consequentemente o efeito na textura.

\section{REFERENCIAS}

ANFALPET. Manual de Sustentabilidade PIQ PET. 5. Ed. São Paulo: Fine Print Artes Gráficas Ltda EPP, 2011.

AZEREDO, Henriette Monteiro Cordeiro de. Fundamentos de estabilidade de alimentos. Fortaleza: Embrapa Agroindústria Tropical, 2004. 195 p. 
ARNOSTI Jr, S.. Desenvolvimento de um secador transportador do tipo esteira com escoamento cruzado e caracterização de sementes de gramíneas, São Carlos, 1997. p. 232. Dissertação (Mestrado). Faculdade de Engenharia Química da UFSCAR, São Carlos - SP, 1997.

FISZMAN, S. Bases teóricas de la determinación de la textura de alimentos sólidos. Curso de Textura Aplicada a Pães, Biscoitos e Massas Alimentícias. p.1-11, ITAL, 1989.

GRANDA, M. K. Aplicação de lípase e monoglicerídeo em pão de forma enriquecido com fibras, Ciência e Tecnologia de Alimentos,Campinas, jan.-mar. 2008. P 182-192.

KROG, N., in Food Emulsions, 3 Ed., Revised and Expanded, Marcel Dekker Inc., New York, 1997, p. 141-188.

KROG, N. et al., in Cereal Foods World, 3 Ed. Dinamarca, 1989.

MUNHOZ, M.P., WEBER, F.H., CHANG, Y.K. Influência de hidrocolóides na textura de gel de amido de milho, 2004. UNICAMP, 2004.

MURAKAMI, F. Y. Impacto da adição de água no processo de Extrusão sobre a digestibilidade e propriedades físico-químicas da dieta para cães, Curitiba, 2010. p.14. Dissertação (Pós graduação). Universidade Federal do Paraná, Curitiba-PR, 2010.

MURRAY, S.M., FLICKINGER, A.E., PATIL, A.R., MERCHEN, N.R., BRENT JR., J.L., FAHEY JR., G.C. In vitro fermentation characteristics of native and processed cereal gains and potato starch using ileal chyme from dogs. Journal Animal Science. 79, 435-444, 2001.

NUNES, A.G., Processos Enzimáticos E Biológicos Na Panificação, 2004. p.4 e 5. Universidade Federal de Santa Catarina, Florianópolis-SC, 2004.

PALMA, E. J.; CICHELLO, M. S. F.; PAVANELLI, A. P. Emulsificantes em Panificação, 2004, Oxiteno S/A Indústria e Comércio, 2004.

SUN, D.-W.; WOOD, J.L. The moisture content/relative humidity equlibrium relationship of wheat - A review. Drying technology, v. 11, p. 1523-1551, 1993. 